Disponível em

http://www.anpad.org.br/rac

RAC, Rio de Janeiro, v. 18, n. 1, art. 6, pp. 96-117, Jan./Fev. 2014

$($ cc) $\mathrm{BY}-\mathrm{NC}$

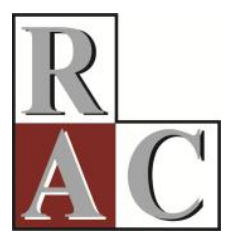

\title{
Facetas do Risco no Empreendedorismo Internacional
}

\section{Facets of Risk in International Entrepreneurship}

Yákara Vasconcelos Pereira Leite

E-mail: yakarav@gmail.com

Universidade Federal Rural do Semi-Árido - UFERSA

UFERSA, Avenida Francisco Mota, 572, Costa e Silva, 59625-900, Mossoró, RN, Brasil.

Walter Fernando Araújo de Moraes

E-mail: walter.moraes@ufpe.br

Universidade Federal de Pernambuco - PROPAD/UFPE

UFPE, Av. Prof Moraes Rego, 1235, Cidade Universitária, 50670901, Recife, PE, Brasil. 


\title{
Resumo
}

Este artigo tem o objetivo de analisar as facetas do risco enfrentado pelo empreendedor no processo de internacionalização. A abordagem de empreendedorismo internacional compôs a sustentação teórica da pesquisa. Um estudo de múltiplos casos qualitativo-longitudinais foi desenvolvido na Agrícola Famosa-CE, Agro MelãoRN (pseudônimo), Special Fruit-BA e Ara Agrícola-PE. Trinta gestores e consultores participaram das entrevistas. A análise de dados contou com o apoio da teoria adaptativa e da análise de conteúdo. Duas facetas do risco emergiram dos dados, a saber: comercial e negociação; e produção agrícola. O câmbio se apresenta como o desafio mais arriscado de comercial e negociação, enquanto que as condições climáticas caracterizam a produção agrícola que influenciam o processo de internacionalização. Portanto, a dimensão comercial e negociação decorre da internacionalização e da atividade do segmento econômico, enquanto que a produção agrícola possui idiossincrasias do agronegócio.

Palavras-chave: empreendedorismo internacional; atitude em face ao risco; internacionalização.

\begin{abstract}
This article aims to analyze the facets of risk experienced by entrepreneurs in the internationalization process. The approach to international entrepreneurship composed the theoretical underpinnings of the research. A longitudinal, qualitative multiple case study was developed for Agrícola Famosa-CE, Agro Melon-RN (pseudonym), Special Fruit-BA and Ara Agrícola-PE. Thirty-one managers and consultants participated in the interviews. Data analysis was supported by adaptive theory and content analysis. Two facets of risk emerged from the data, namely: commercial and negotiation, and agricultural production. The exchange rate is presented as the most challenging property from the commercial and negotiation facet, while climatic conditions characterize the agricultural production that influences the internationalization process. Therefore, the commercial and negotiation facet stems from internationalization and economic activity in the segment, while agricultural production has agribusiness idiosyncrasies.
\end{abstract}

Key words: international entrepreneurship; attitude towards risk; internationalization. 


\section{Introdução}

A internacionalização de empresas é um fenômeno também presente nos países em desenvolvimento. Diante da sua importância, passou a ser uma das atividades fundamentais na geração de emprego e renda, o que vem despertando a atenção de empresários e governantes. Nesse cenário, o agronegócio contribui para que o Brasil seja líder de exportação mundial de açúcar, café e soja. Frutas, carnes, amêndoas, cereais, dentre outros produtos, também fazem parte do setor (Ministério da Agricultura, Pecuária e Abastecimento [MAPA], 2011a).

A exportação de produtos do agronegócio está presente em regiões brasileiras como a do semiárido, destacando-se a fruticultura irrigada. Na denominação do Ministério da Agricultura, Pecuária e Abastecimento (MAPA), fazem parte da fruticultura: conservas e preparações de frutas (exceto sucos); frutas congeladas, frescas e secas; nozes e castanhas. As exportações desse segmento cresceram 4,02\%, no ano de 2010, em relação aos resultados de 2009 (MAPA, 2011b), sendo a região semiárida propícia ao cultivo de frutas tropicais, o que favorece a oferta de produtos de qualidade, reconhecidos internacionalmente.

Para alcançar essa inserção nas exportações, alguns obstáculos vêm sendo ultrapassados. Ao mesmo tempo em que há condições naturais favoráveis ao cultivo de determinados produtos, por outro lado, existem dificuldades, a exemplo da distância dos portos para exportação, instabilidade climática, preço dependente do mercado, câmbio da moeda, condições do solo, risco de pragas, dependência da tecnologia para o plantio, restrita disponibilidade de recursos financeiros e de pessoal capacitado. Dentre outras causas, as incertezas da demanda e da produção internacional influenciam significativamente a definição dos preços.

Ao vivenciar situações adversas da localidade, como também da própria atividade da fruticultura e da legislação comercial dos países de destino, acredita-se que ações empreendedoras voltadas à conquista do mercado internacional são primordiais para as empresas da região. Como reconhecido na literatura, os empreendedores são fundamentais na identificação e na exploração de oportunidades internacionais face ao enfrentamento de riscos (Nassif, Ghobril, \& Silva, 2010; Schweizer, Vahlne, \& Johanson, 2010).

Para ultrapassar os diversos fatores para se internacionalizar, os empresários do semiárido passaram a atuar num ambiente complexo, o que requer certa propensão ao enfrentamento de riscos. Com isso, parece oportuno investigar as exportadoras de frutas dessa região, a luz do arcabouço teórico de empreendedorismo internacional (Mtigwe, 2006). Desse modo, o artigo tem o objetivo de analisar as facetas do risco enfrentado pelo empreendedor no processo de internacionalização.

\section{Referencial Teórico}

Neste estudo ${ }^{(1)}$, compreende-se o empreendedorismo internacional numa perspectiva processual. Logo, o entendimento que parece estar melhor alinhado ao objetivo de pesquisa é o de Van de Ven (1992), por afirmar que é preciso defini-lo primeiramente. Assim, a internacionalização é reconhecida como um processo de estratégia que ocorre em uma sequência de estágios (Melin, 1992) e eventos, numa concepção de desenvolvimento histórico da empresa, provocados por ações individuais e organizacionais (Van de Ven, 1992).

Diante disso, observam-se os desafios que perpassam a internacionalização e o papel do dirigente nesse processo. O empreendedorismo internacional (EI) surge como uma orientação teórica que enfatiza questões que não foram amplamente discutidas nos modelos clássicos de internacionalização e empreendedorismo. Morrow (1988) foi o primeiro a escrever sobre o tema, todavia, McDougall (1989) é considerada pioneira por realizar a primeira pesquisa teórico-empírica (Acs, Dana, \& Jones, 2003). 
Em 2009, o estudo de empreendedorismo internacional completou duas décadas, fato que motivou a elaboração de estudos bibliográficos que sumarizam e avaliam o seu estado da arte (Coombs, Sadrieh, \& Annavarjula, 2009; Coviello \& Jones, 2004; Coviello, McDougall, \& Oviatt, 2011; Jones, Coviello \& Tang, 2011; Keupp \& Gassmann, 2009; Kiss, Danis, \& Cavusgil, 2012).

Ao analisar o enfoque teórico dessas referências, são apontadas algumas considerações. A premissa principal desse campo é que a internacionalização é uma condição necessária para a sobrevivência do empreendimento (Coombs et al., 2009), e a comercialização com o exterior está no centro da discussão e traz vantagens empresariais, como a ampliação da possibilidade de lucros.

O EI possui características que o distingue do empreendedorismo tradicional (Leite \& Moraes, 2012). O empreendedorismo está relacionado à criação de um novo negócio por parte do empreendedor (Filion, 1999; Oliveira, 2011). Mas, no empreendedorismo internacional, a questão não se limita à criação de negócios, o ponto central consiste na forma em que ocorre o processo de internacionalização. O empreendedorismo internacional está presente nas firmas que se internacionalizam por meio de ações empreendedoras que podem ou não ser implementadas pelo proprietário (Dimitratos \& Plakoyiannaki, 2003).

No empreendedorismo internacional, o risco está no investimento realizado para atender o mercado internacional, na negociação com os compradores que muitas vezes não têm garantias de pagamento (McDougall, 1989) e no modo de entrada no exterior (Welch \& Welch, 2004). O risco, além de ser um fator preponderante na literatura clássica de empreendedorismo, vem ganhando espaço nos estudos de internacionalização.

Ao relacionar os trabalhos de Zahra e George (2002), Oviatt e McDougall (1994) e Dimitratos e Plakoyannaki (2003), identificam-se semelhanças. Essas pesquisas têm a tomada de risco como elemento primordial para o empreendedorismo internacional. No mesmo sentido, verifica-se que o modo como o empreendedor enfrenta os riscos para se internacionalizar está na essência do EI (Freitag \& Amal, 2008; Rossi, 2008). A propensão ao risco é inevitável nessa abordagem teórica. O empreendedor não atua de forma irresponsável, porém, o fato de estar mais propenso a enfrentar determinadas situações para se internacionalizar é o que o diferencia das demais pessoas (Mello, Rocha, \& Maculan, 2009).

Em geral, o empreendedor se relaciona com os riscos para explorar oportunidades nas transações do negócio. Os modos de perceber e enfrentar o risco são atributos do empreendedor (Dimitratos \& Plakoyiannaki, 2003), justificados pelas expectativas de retornos superiores quando se trata de realizar novas e surpreendentes ações (McCarthy \& Leavy, 1999), como o que acontece na decisão de internacionalizar.

A propensão ao risco, de acordo com Grichnik (2008, p. 25), é o "traço da personalidade do tomador de decisão que influencia o comportamento de tomada de risco, mas não o determina". Os traços da personalidade do empreendedor e a sua percepção apresentam-se como propulsores da tomada de risco.

O risco abordado neste estudo é aquele enfrentado pelos empreendedores para internacionalizar a empresa que depende da disposição de comprometer recursos (Lumpkin \& Dess, 1996). Existem mais alguns tipos de riscos no processo de internacionalização, a exploração de oportunidades por si é arriscada (Johanson \& Vahlne, 2009), os gestores podem tomar decisões que sejam negativas à empresa. Outra fonte de riscos é a utilização dos modos de entrada. Sharma e Erramili (2004) apresentam quatro tipos de modos de entrada nos mercados internacionais (exportações diretas e indiretas, modelos contratuais, joint ventures e estabelecimento de subsidiárias) e enfatizam que cada um deles não apenas é fonte de vantagem competitiva, como também de riscos.

Mas, para reduzir tais riscos, Melin (1992) argumenta que a internacionalização gradual iniciada com a exportação favorece a aprendizagem e mitiga os riscos. Quando o empresário decide fazer investimentos diretos, a aquisição de negócios em mercados estrangeiros é uma opção para reduzir o risco por adquirir a propriedade em pleno funcionamento (Schweizer et al., 2010). 
Quanto aos riscos de negociação, os empreendedores podem fazer uso dos contratos formais para tentar reduzir os custos de transação. Williamson (1995) apresenta os contratos como um elemento da governança que é mediadora na relação dos indivíduos com o ambiente institucional. De forma complementar, Child e Rodrigues (2007, p. 3) argumentam que a "confiança contribui positivamente na colaboração internacional porque os contratos formais por si, raramente são suficientes para garantir a sua eficácia, e pode ser difícil e caro fazer cumpri-los".

Quanto aos riscos relacionados às exportadoras do agronegócio, não apenas se originam no ambiente internacional, mas também, no doméstico. Os resultados da pesquisa de Welch e Welch (2004) permitem afirmar que os riscos podem ser minimizados se a política de incentivo à exportação estiver favorável ao investidor. O governo do país de origem muitas vezes tem o poder de lançar políticas de proteção e incentivo. As atividades agropecuárias estão sujeitas a dois tipos de riscos: o de produção agrícola (dependente das condições naturais) e o risco de negociação (relacionado às condições econômicas e de preço) (Ramos, 2007).

A forma de perceber os riscos está ligada aos traços de personalidade, assim como ao sistema de crenças e valores compartilhados pelos sujeitos, o que remete à questão do porte e tempo da empresa. Quando o empreendimento internacionalizado é pequeno, a atitude face ao risco em relação à capacidade de inovar e à orientação frente aos consumidores é essencial (Dib, 2008). No que concerne ao tempo de vida, o novo empreendimento internacional é afeto ao risco com objetivo de criação de valor, enquanto que a empresa internacional amadurecida tende a ser avessa ao risco para sobreviver (Mello et al., 2009).

A Tabela 1 mostra a síntese da revisão de literatura de risco apresentada nesta seção. As facetas e as suas características podem ser decorrentes da internacionalização, da organização e da atividade do agronegócio, assim como há tipos de riscos com origem híbrida, a exemplo do porte, tempo de atuação e negociação.

Tabela 1

\section{Facetas do Risco}

\begin{tabular}{|c|c|c|c|}
\hline Facetas do risco & Características das facetas & Origens do risco & Base teórica \\
\hline $\begin{array}{l}\text { Processo de } \\
\text { internacionalização }\end{array}$ & $\begin{array}{l}\text { Necessidade de aprimorar os } \\
\text { processos e produtos para atuar em } \\
\text { mercados estrangeiros. }\end{array}$ & Internacionalização & McDougall (1989) \\
\hline $\begin{array}{l}\text { Negociação com os } \\
\text { compradores }\end{array}$ & $\begin{array}{l}\text { Ausência de garantias de } \\
\text { pagamento. }\end{array}$ & Internacionalização & McDougall (1989) \\
\hline $\begin{array}{l}\text { Modo de entrada no } \\
\text { exterior }\end{array}$ & $\begin{array}{l}\text { Cada tipo de entrada possui } \\
\text { diferentes graus de } \\
\text { comprometimento de recursos. }\end{array}$ & Internacionalização & $\begin{array}{l}\text { Welch e Welch (2004); } \\
\text { Sharma e Erramili } \\
(2004)\end{array}$ \\
\hline $\begin{array}{l}\text { Exploração de } \\
\text { oportunidades } \\
\text { internacionais }\end{array}$ & $\begin{array}{l}\text { Comprometimento de recursos e da } \\
\text { sobrevivência organizacional. }\end{array}$ & Internacionalização & $\begin{array}{l}\text { Dimitratos e } \\
\text { Plakoyiannaki (2003); } \\
\text { Johanson e Vahlne } \\
\text { (2009) }\end{array}$ \\
\hline Porte & $\begin{array}{l}\text { Quanto menor estiver a empresa, } \\
\text { existe mais flexibilidade e } \\
\text { propensão ao enfrentamento de } \\
\text { riscos internacionais. }\end{array}$ & $\begin{array}{l}\text { Internacionalização/ } \\
\text { Organização (empresa) }\end{array}$ & Dib (2008) \\
\hline
\end{tabular}




\section{Tabela 1 (continuação)}

\begin{tabular}{llll}
\hline Facetas do risco & Características das facetas & Origens do risco & Base teórica \\
\hline Tempo de atuação & $\begin{array}{l}\text { As empresas mais novas tendem a } \\
\text { se arriscarem mais no ambiente } \\
\text { internacional. }\end{array}$ & $\begin{array}{l}\text { Internacionalização/ } \\
\text { Organização (empresa) }\end{array}$ & $\begin{array}{l}\text { Mello, Rocha e Maculan } \\
(2009)\end{array}$ \\
Produção agrícola & $\begin{array}{l}\text { Dependente das condições naturais } \\
\text { como clima, solo etc. }\end{array}$ & $\begin{array}{l}\text { Atividade do } \\
\text { agronegócio }\end{array}$ & Ramos (2007) \\
Negociação & $\begin{array}{l}\text { Relacionado as condições } \\
\text { econômicas, preços e câmbio. }\end{array}$ & $\begin{array}{l}\text { Atividade do } \\
\text { agronegócio/ } \\
\text { Internacionalização }\end{array}$ & $\begin{array}{l}\text { Ramos (2007); Welch e } \\
\text { Welch (2004) }\end{array}$ \\
\hline
\end{tabular}

Nota. Fonte: Elaborado pelos autores.

Para atingir o objetivo proposto neste artigo, pode-se observar na literatura revisada que as facetas formam tipos de riscos enfrentados pelos dirigentes, sejam relacionados a internacionalização, organização ou atividade do agronegócios. Além disso, as características dessas facetas são apresentadas no intuito de viabilizar a identificação na expresividade do fenômeno. Portanto, passa-se para a exposição dos aspectos metodológicos.

\section{Procedimentos Metodológicos}

Esta pesquisa segue as recomendações da Teoria Adaptativa. Nela, a teoria é construída com base no background teórico e nos dados empíricos. É adotada a perspectiva qualitativa que foca a essência, o entendimento e a descrição (Bogdan \& Biklen, 1994; Guba \& Lincoln, 2005). Para tanto, adota-se a estratégia de estudo de múltiplos casos, utilizada no sentido de construir teoria (Eisenhardt, 1989). Assim, tem-se o estudo de caso qualitativo histórico (Merriam, 1998). Trata-se de uma pesquisa de natureza longitudinal, que contou com o apoio do software ATLAS.ti versão 7, na fase de análise dos dados.

Após o estudo de cada uma das empresas, considerou-se o exame entre os casos, denominandose análise cruzada (Merriam, 1998; Stake, 1995). A decisão de selecionar empresas que atuam no segmento da fruticultura está em consonância com as recomendações de Eisenhardt (1989), que indica, na construção de teorias, o estudo de múltiplos casos. Quatro empresas, representantes dos Estados da Bahia, Ceará, Pernambuco e Rio Grande do Norte, foram selecionadas. Tal decisão foi motivada ao considerar os indicadores de janeiro a setembro de 2011, que demonstravam que esses Estados são responsáveis por aproximadamente $100 \%$ do total de frutas exportadas no semiárido.

Os indivíduos e os casos foram selecionados pelo critério de conveniência, devido ao acesso às informações (Merriam, 1998). Por ser um estudo qualitativo e diante da natureza do fenômeno, diferentes técnicas de coleta de dados foram utilizadas, dentre elas, a entrevista semiestruturada e a análise de documentos e de material bibliográfico sobre a região (Patton, 2001). A entrevista semiestruturada permite que o pesquisador redirecione as perguntas conforme a evolução da pesquisa (Bogdan \& Biklen, 1994). As entrevistas foram gravadas e transcritas, perfazendo 1.242 minutos no total e uma média de 40 minutos por entrevistado, acontecendo em dois momentos distintos. Após a primeira coleta de dados primários ( $1^{\mathrm{a}}$ etapa), as informações foram analisadas de modo exploratório, assim, identificaram-se algumas incongruências e contradições motivando o retorno ao campo para validar e consolidar a interpretação dos dados. Por essa técnica, cada um dos 30 respondentes foi entrevistado e apenas o gerente comercial de exportação da Agrícola Famosa foi entrevistado novamente, totalizando 31 entrevistas.

Anterior à coleta de dados, realizou-se um estudo piloto na Brazil Melon, localizada em Mossoró$\mathrm{RN}$, com porte e estrutura agrícola semelhantes aos da Agro Melão. Indica-se que as anotações sobre o 
estudo piloto e a coleta de dados primários (entrevistas) foram registradas no diário de campo digital. Adotou-se a análise de conteúdo (Bardin, 2011), considerando os aspectos contextuais, para identificar conexões, códigos e categorias existentes nas transcrições das entrevistas. Para alcançar o rigor científico esperado na academia, a análise de dados contemplou três passos, quais sejam: descrição, inferência e interpretação. Durante a análise de dados, buscaram-se validação e confiabilidade científica (Paiva, Leão, \& Mello, 2011). Os critérios utilizados para validação e confiabilidade foram: triangulação (uso de múltiplas fontes de informação e de técnicas de coleta de dados); construção do corpus de pesquisa (representatividade e tamanho da amostra); descrição clara, rica e detalhada; e feedback dos informantes (validação comunicativa). Adotou-se ainda os critérios de surpresa (validação) e reflexividade (confiabilidade).

Por fim, revelam-se as pricipais ferramentas adotadas do ATLAS.ti. A Tabela 2 sintetiza as atividades realizadas na investigação com o software. Observam-se na primeira coluna os objetivos, as ferramentas do sistema utilizadas e os resultados alcançados.

Tabela 2

Ferramentas do ATLAS.ti Utilizadas na Pesquisa

\begin{tabular}{|c|c|c|}
\hline Finalidades & Ferramentas do ATLAS.ti & Resultados obtidos \\
\hline Criação do arquivo & $\begin{array}{l}\text { Salvo como nova unidade } \\
\text { hermenêutica }\end{array}$ & $\begin{array}{l}\text { Arquivo salvo e, junto com ele, o } \\
\text { backup automático que não deve } \\
\text { ser deletado. }\end{array}$ \\
\hline $\begin{array}{l}\text { Inclusão das entrevistas, teses, } \\
\text { dissertações, artigos e informações } \\
\text { obtidas no site do MDIC. }\end{array}$ & . Adição de documentos & . Geração de: P-Docs. \\
\hline Codificação (Bardin, 2011) & $\begin{array}{l}\text { Seleção de trechos do documento, } \\
\text { deve-se clicar no botão direito do } \\
\text { mouse em: create free cotation } \\
\text { (para as novas) e coding (para } \\
\text { adicionar trechos aos códigos } \\
\text { existentes). }\end{array}$ & $\begin{array}{l}\text { Geração de codes e quotes } \\
\text { (citações). }\end{array}$ \\
\hline $\begin{array}{l}\text { Memorandos - "registros escritos } \\
\text { de análise que podem variar em tipo } \\
\text { e formato" (Strauss \& Corbin, } \\
\text { 2008, p. 207). }\end{array}$ & $\begin{array}{l}\text { Está no botão direito do mouse ou } \\
\text { na barra de ferramenta (memos). } \\
\text { Podem ser interligados aos relatos } \\
\text { selecionados, códigos ou ficam } \\
\text { independentes. }\end{array}$ & . Geração de memos. \\
\hline $\begin{array}{l}\text { Comentários - registros sobre a } \\
\text { codificação, a teoria e } \\
\text { operacionalização metodológica } \\
\text { (Strauss \& Corbin, 2008). }\end{array}$ & $\begin{array}{l}\text { Está no botão direito do mouse. } \\
\text { Podem se relacionar aos códigos e } \\
\text { aos memorandos. }\end{array}$ & Geração de comments. \\
\hline Categorização (Bardin, 2011) & $\begin{array}{l}\text { Realizada de duas formas: criação } \\
\text { de famílias de códigos no menu } \\
\text { codes e considerando alguns } \\
\text { códigos (codes) como categorias. } \\
\text { Recomendação realizada por } \\
\text { Friese (2012), pois os códigos } \\
\text { possuem mais opções de análise e } \\
\text { flexibilidade na versão } 7 \text { do } \\
\text { sistema. }\end{array}$ & . Geração de code family e codes. \\
\hline
\end{tabular}




\section{Tabela 2 (continuação)}

\begin{tabular}{|c|c|c|}
\hline Finalidades & Ferramentas do ATLAS.ti & Resultados obtidos \\
\hline $\begin{array}{l}\text { Relação entre códigos, categorias e } \\
\text { memorandos. }\end{array}$ & $\begin{array}{l}\text { Ferramentas utilizadas: network e } \\
\text { links. } \\
\text { O programa apresenta um } \\
\text { conjunto de links que pode ser } \\
\text { adotado, e a opção de criar links. } \\
\text {. Utilizaram-se: is associated with; } \\
\text { is part of; is cause of; is a. } \\
\text {. Foi criada: "antecede" para } \\
\text { representação cronológica dos } \\
\text { eventos marcantes da } \\
\text { internacionalização. }\end{array}$ & . Geração de links. \\
\hline $\begin{array}{l}\text { Representação gráfica dos } \\
\text { relacionamentos entre códigos, } \\
\text { categorias, memorandos, } \\
\text { comentários e links. }\end{array}$ & Ferramenta utilizada: network. & . Geração de: networks. \\
\hline Contagem de palavras & $\begin{array}{l}\text { Na barra de ferramentas, acessa- } \\
\text { se: analysis: word cruncher. }\end{array}$ & $\begin{array}{l}\text { Geração de contagem de palavras } \\
\text { e percentuais (pode ser solicitado } \\
\text { em excel) }\end{array}$ \\
\hline $\begin{array}{l}\text { Identificação da "presença ou } \\
\text { ausência" em conjunto com a } \\
\text { "coocorrência" (Bardin, 2011, pp. } \\
\text { 259-260). }\end{array}$ & $\begin{array}{l}\text { Na barra de ferramentas, acessa-se } \\
\text { analysis: code cooccurrence table } \\
\text { e cluster quotations before } \\
\text { calculating co-occurrence. }\end{array}$ & $\begin{array}{l}\text { Geração de planilha para observar } \\
\text { interseção entre trechos, códigos e } \\
\text { categorias (pode ser solicitada em } \\
\text { Excel). }\end{array}$ \\
\hline Relatório final do programa & $\begin{array}{l}\text { Dois tipos foram solicitados em } \\
\text { project: } \text { output; all objects e all } \\
\text { objects }(\text { grouped }) \text {. }\end{array}$ & $\begin{array}{l}\text { Geração de relatórios ordenados } \\
\text { por data de criação e por grupo. }\end{array}$ \\
\hline
\end{tabular}

Nota. Fonte: Elaborado pelos autores.

A análise de dados no programa foi concluída com 45 documentos, 9.521 palavras (sem repetições), 2.087 trechos selecionados e codificados, 345 códigos, 64 categorias (incluem-se aqui os códigos considerados categorias e famílias de códigos), 69 memorandos e 59 redes.

\section{Análise dos Resultados}

A discussão dos resultados está organizada em duas etapas: a primeira apresenta os tipos de risco por empresa de forma individual; a segunda, expõe a análise cruzada dos casos.

\section{Manifestações do risco}

\section{Agrícola Famosa-CE}

A Agrícola Famosa é a maior exportadora internacional de melão, com registro fiscal no município de Icapuí-CE, e produtora em 20.807 hectares. Atualmente, a empresa possui cinco fazendas próprias, com total de 14.999 hectares, e oito arrendadas, com 5.808 hectares (Agrícola Famosa, 2012). Trata-se de uma born global - empreendimento que nasce global, para se internacionalizar (Rennie, 1993) - fundada para exportar melão, em 1995. Esse posicionamento estratégico foi herdado pela experiência adquirida por um dos sócios-fundadores no tempo que geria sua trading company, anterior à concepção da Agrícola Famosa. 
O processo de internacionalização da Agrícola Famosa está demarcado em quatro fases com treze eventos, na Figura 1. A primeira se constitui por três eventos marcantes (AF-Evento 1; AF-Evento 2; AF-Evento 3), assim como a segunda (AF-Evento 4; AF-Evento 5; AF-Evento 6). Já a terceira possui quatro (AF-Evento 7; AF-Evento 8; AF-Evento 9; AF-Evento 10), sendo a última representada por três deles (AF-Evento 11; AF-Evento 12; AF-Evento 13). As setas com flechas duplas fazem a conexão entre as fases (code family) e os eventos (code) que as compõem, nelas não é possível incluir (escrever) o tipo de link, apenas se indica a existência de relação. O mesmo ocorre com os memorandos (memos) e as citações (quotes). As setas entre os eventos são de dois tipos, a saber: antecedente, que exprime uma relação de sequência entre os eventos, e is cause of (é causa de), que mostra o evento que causa outro. Ressalta-se que os memos (memorandos) e comments (comentários), ambos recursos do ATLAS.ti, foram omitidos, assim como a maior parte dos trechos citados pelos respondentes devido à limitação gráfica.

A Agrícola Famosa foi a única a entrar no mercado internacional com uma subsidiária integral. Para materializar o intento estratégico de fornecer frutas durante os 12 meses do ano, a Agrícola Famosa inaugurou uma subsidiária no Senegal (África), para plantar melão no exterior. É um dos modos de entrada que requer mais envolvimento e comprometimento dos dirigentes, por ter elevado capital investido diretamente no empreendimento (Root, 1994).

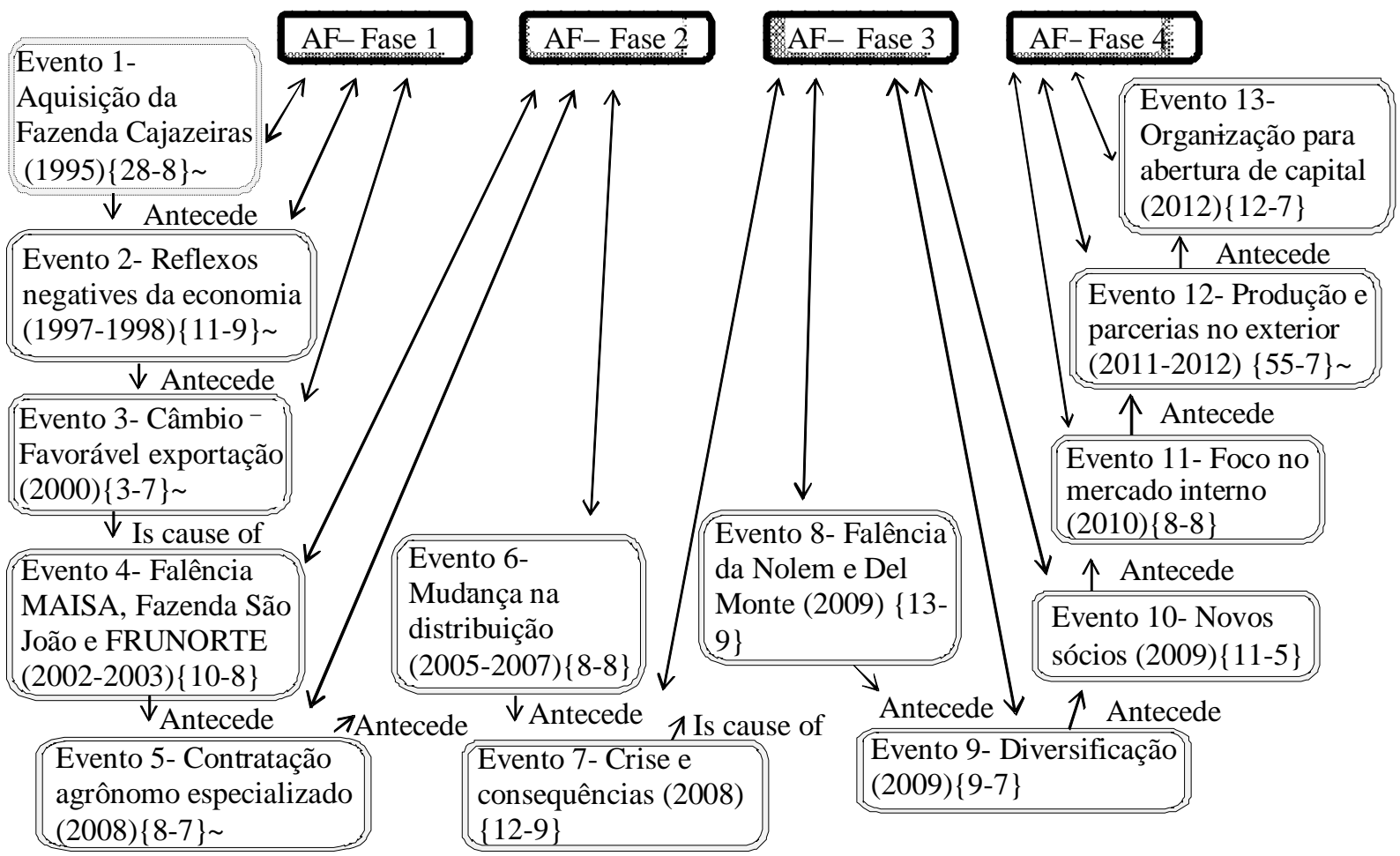

Figura 1. Processo de Internacionalização da Agrícola Famosa (1995-2012).

Nota. Fonte: Elaborado pelos autores.

Os comandos de análise cruzada do ATLAS.ti code cooccurrence table e cluster quotations before calculating co-occurrence viabilizaram a interpretação e a classificação consolidadas nas Figuras dessa seção. A Tabela 3 proporciona a visualização da presença (áreas de cor preta) das facetas do risco nos eventos do processo de internacionalização da Agrícola Famosa. Na primeira coluna, são apresentadas as facetas (subcategorias) e nas demais colunas, as fases e os eventos marcantes (de E1 a E13). Pode-se perceber que as facetas do risco estão expressas em diferentes fases ao longo da trajetória da empresa, destacando-se a de âmbito comercial e negociação que revela-se em três eventos. 
Tabela 3

Expressão das Facetas e Características do Risco no Processo de Internacionalização da Agrícola Famosa

\begin{tabular}{|c|c|c|c|c|c|c|c|c|c|c|c|c|c|}
\hline \multirow{3}{*}{$\begin{array}{l}\text { Facetas e suas } \\
\text { características }\end{array}$} & \multirow{2}{*}{\multicolumn{3}{|c|}{$\begin{array}{l}\text { Fase } 1 \\
1995-2001\end{array}$}} & \multicolumn{3}{|c|}{ Fase 2} & \multicolumn{3}{|c|}{ Fase 3} & \multicolumn{4}{|c|}{ Fase 4} \\
\hline & & & & \multicolumn{3}{|c|}{ 2002-2007 } & \multicolumn{3}{|c|}{ 2008-2009 } & \multicolumn{4}{|c|}{ 2010-2012 } \\
\hline & E1 & E2 & $\mathbf{E 3}$ & $\mathbf{E 4}$ & E5 & E6 & E7 & E8 & E9 & E10 & E11 & E12 & E13 \\
\hline \multicolumn{14}{|l|}{ Câmbio } \\
\hline \multicolumn{14}{|l|}{ Comercial e negociação } \\
\hline \multicolumn{14}{|l|}{ Condições climáticas } \\
\hline \multicolumn{14}{|l|}{ Distribuição } \\
\hline \multicolumn{14}{|l|}{ Empresa de grande porte } \\
\hline \multicolumn{14}{|l|}{ Novos mercados } \\
\hline \multicolumn{14}{|l|}{ Produção agrícola } \\
\hline \multicolumn{14}{|l|}{ Produção e parcerias } \\
\hline Variedades & & & & & & & & & & & & & \\
\hline
\end{tabular}

Nota. Fonte: Elaborado pelos autores.

Os dados coletados permitem apresentar as facetas do risco enfrentadas pela Agrícola Famosa (ver Figura 2). Os empreendedores assumiram riscos de ordem comercial e de negociação (câmbio e novos mercados), relacionados à produção agrícola (condições climáticas, variedades e produção e parcerias no exterior), distribuição e também os advindos do porte da empresa.

Verifica-se que a comercialização e a negociação na fruticultura demandam ousadia dos empreendedores frente aos riscos da atividade, especialmente devido à falta de hábito em definir contratos formais e, quando elaborados, do seu cumprimento. Nesse sentido, os relacionamentos minimizam a percepção de risco por parte dos dirigentes, evidência que está em consonância com o pensamento de Williamson (1995). 


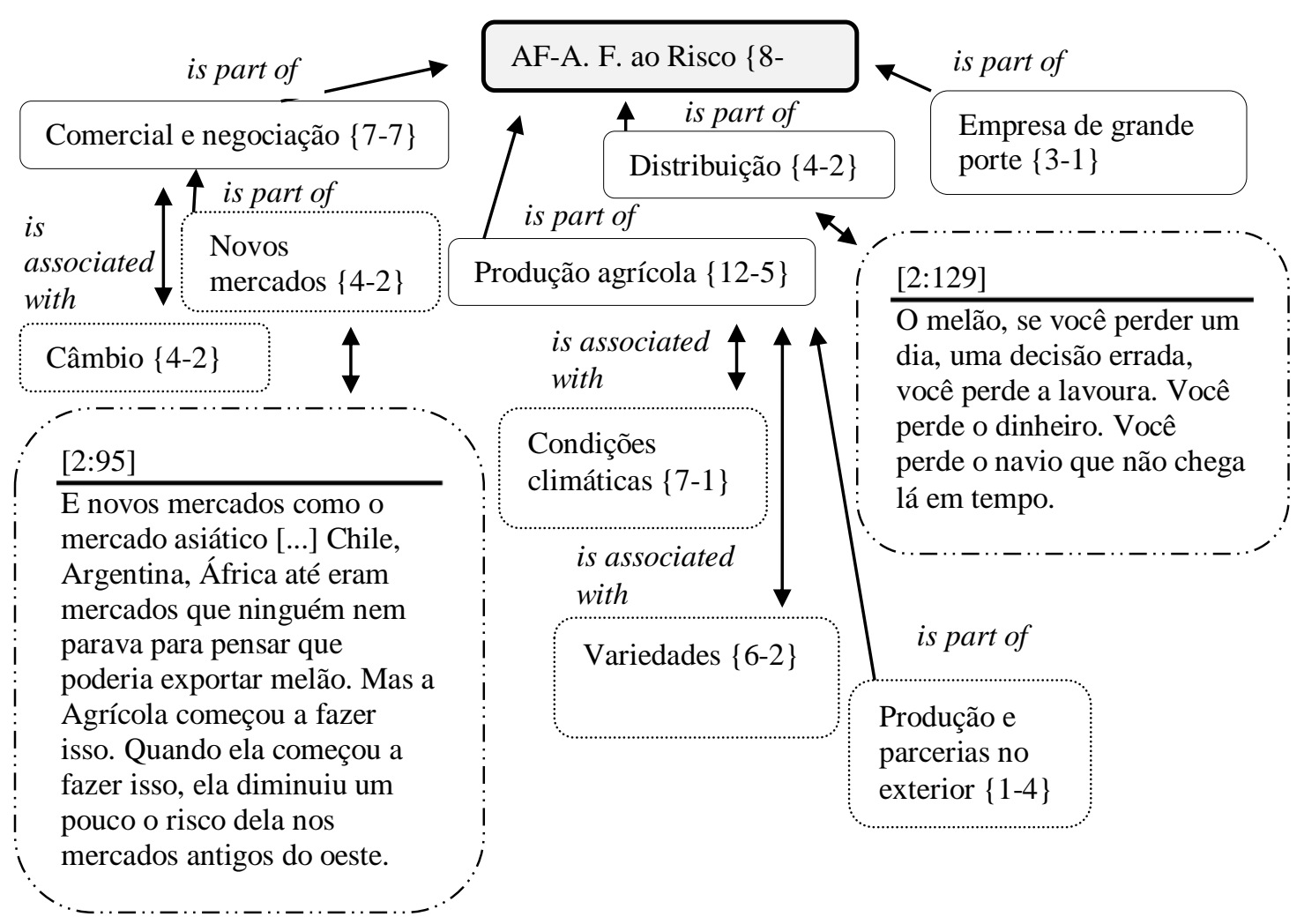

Figura 2. Facetas do Risco (Agrícola Famosa).

Nota. Fonte: Elaborado pelos autores.

Outrossim, a variação cambial determina o direcionamento da quantidade de produtos exportáveis frente aos disponibilizados no mercado doméstico, decisão arriscada que pode comprometer a rentabilidade do negócio. Portanto, faz parte dessa discussão a entrada em novos mercados (Root, 1994), que envolve a definição dos dirigentes e a disponibilidade de recursos humanos para captar clientes além fronteira nacional.

\section{Agro Melão-RN}

A Agro Melão é considerada a segunda maior produtora de melão da região, com 1.000 hectares e fundada em setembro de 1997. O endereço fiscal, o escritório administrativo e parte da fazenda estão situados em Mossoró-RN, e no Ceará existe outra unidade produtiva. A empresa foi constituída para exportar, posicionamento de internacionalização influenciado pela experiência e formação profissional do fundador da firma. Trata-se de uma born global que desde o primeiro ano exporta (Rennie, 1993). Na Figura 3, observam-se as três fases do processo de internacionalização da Agro Melão. O AM-Evento 1, AM-Evento 2 e AM-Evento 3 fazem parte da fase 1. Os eventos AM-Evento 4 e AM-Evento 5 se configuram na segunda fase, enquanto que o AM-Evento 6, AM-Evento 7 e AM-Evento 8 estão na fase 3. 


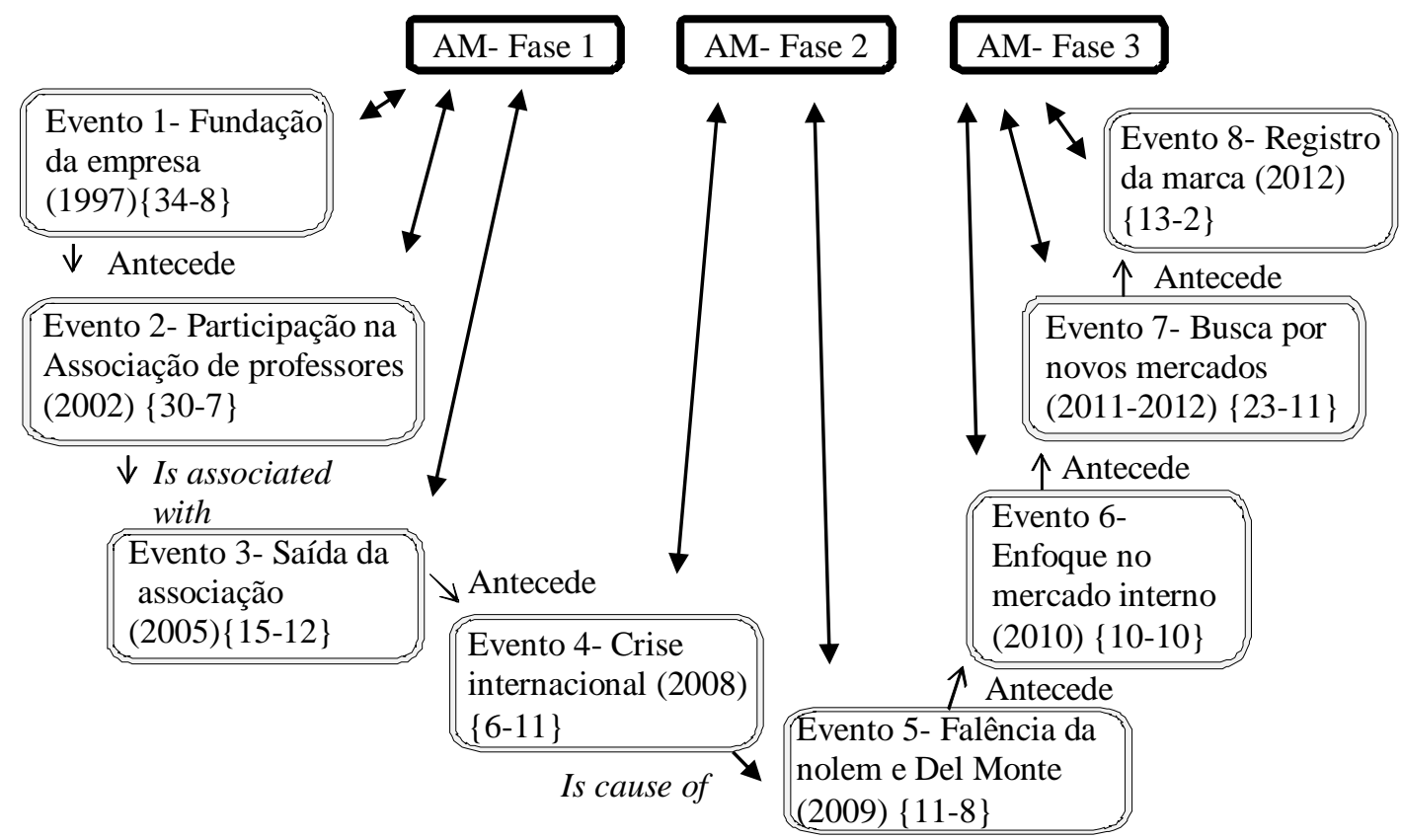

Figura 3. Processo de Internacionalização da Agro Melão (1997-2012).

Nota. Fonte: Elaborado pelos autores.

A presença das indiossincrasias do risco é observada na Tabela 4. A matriz permite a visualização geral em cada fase e evento do processo de internacionalização.

Tabela 4

Expressão das Facetas e Características do Risco no Processo de Internacionalização da Agro Melão

\begin{tabular}{lllllllll}
\hline Facetas e suas características & \multicolumn{1}{l}{ Fase 1 } & \multicolumn{3}{l}{ Fase 2 } & \multicolumn{3}{l}{ Fase 3 } \\
\cline { 2 - 8 } & \multicolumn{1}{l}{ 1997-2007 } & & 2008-2009 & 2010-2012 & \\
\cline { 2 - 8 } & E1 & E2 & E3 & E4 & E5 & E6 & E7 & E8 \\
\hline Comercial e negociação & & & & & & & & \\
Câmbio & & & & & & & & \\
Condições climáticas & & & & & & & & \\
Distribuição & & & & & & & & \\
Produção agrícola & & & & & & & & \\
\hline
\end{tabular}

Nota. Fonte: Elaborado pelos autores.

As decisões para enfrentar os riscos aconteceram nas atividades: comercial e de negociação (considera-se o câmbio), produção agrícola (inclui-se a condição climática) e distribuição (Figura 4). 


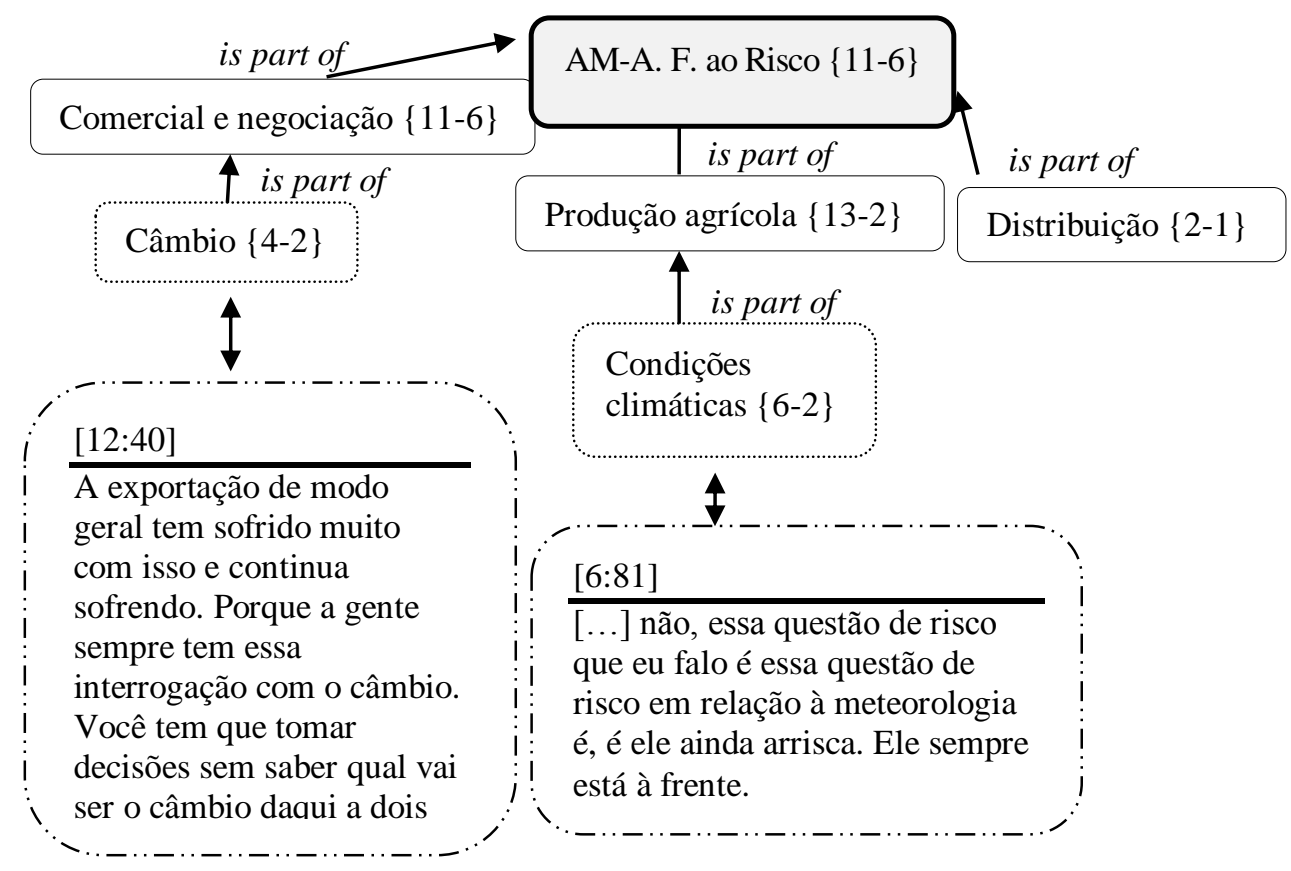

Figura 4. Facetas do Risco (Agro Melão).

Nota. Fonte: Elaborado pelos autores.

Nas entrevistas, os gestores e o empreendedor (Entrevistado-RNeCE_14) mostraram-se conscientes dos riscos provenientes, em especial, dessas origens, compreendendo que, para atuar na exportação de frutas frescas, o empreendedor não tem outra escolha se não a de enfrentar as situações arriscadas. $\mathrm{O}$ empreendedor da fruticultura precisa ser tolerante às incertezas que, de acordo com Butler, Doktor e Lins (2010), tal tolerância antecede a identificação de oportunidades que, por sua vez, exige criatividade para explorá-las.

\section{Special Fruit-BA}

A Special Fruit é reconhecidamente uma empresa de sucesso, com mais de 1.700 funcionários e 600 ha dedicados à manga e à uva (http://www.fazendaspecialfruit.com, recuperado em 25, outubro, 2012). Embora a pretensão inicial não tenha sido a internacionalização, a empresa pode ser classificada como uma born global (Rennie, 1993) por ter se inserido rapidamente no comércio exterior.

Três fases demarcam a biografia da Special Fruit, conforme representação gráfica na Figura 5. A primeira possui três eventos (SF-Evento 1; SF-Evento 2; SF-Evento 3), a segunda quatro (SF-Evento 4; SF-Evento 5; SF-Evento 6; SF-Evento 7) e cinco na terceira (SF-Evento 8; SF-Evento 9; SF-Evento 10; SF-Evento 11; SF-Evento 12). 


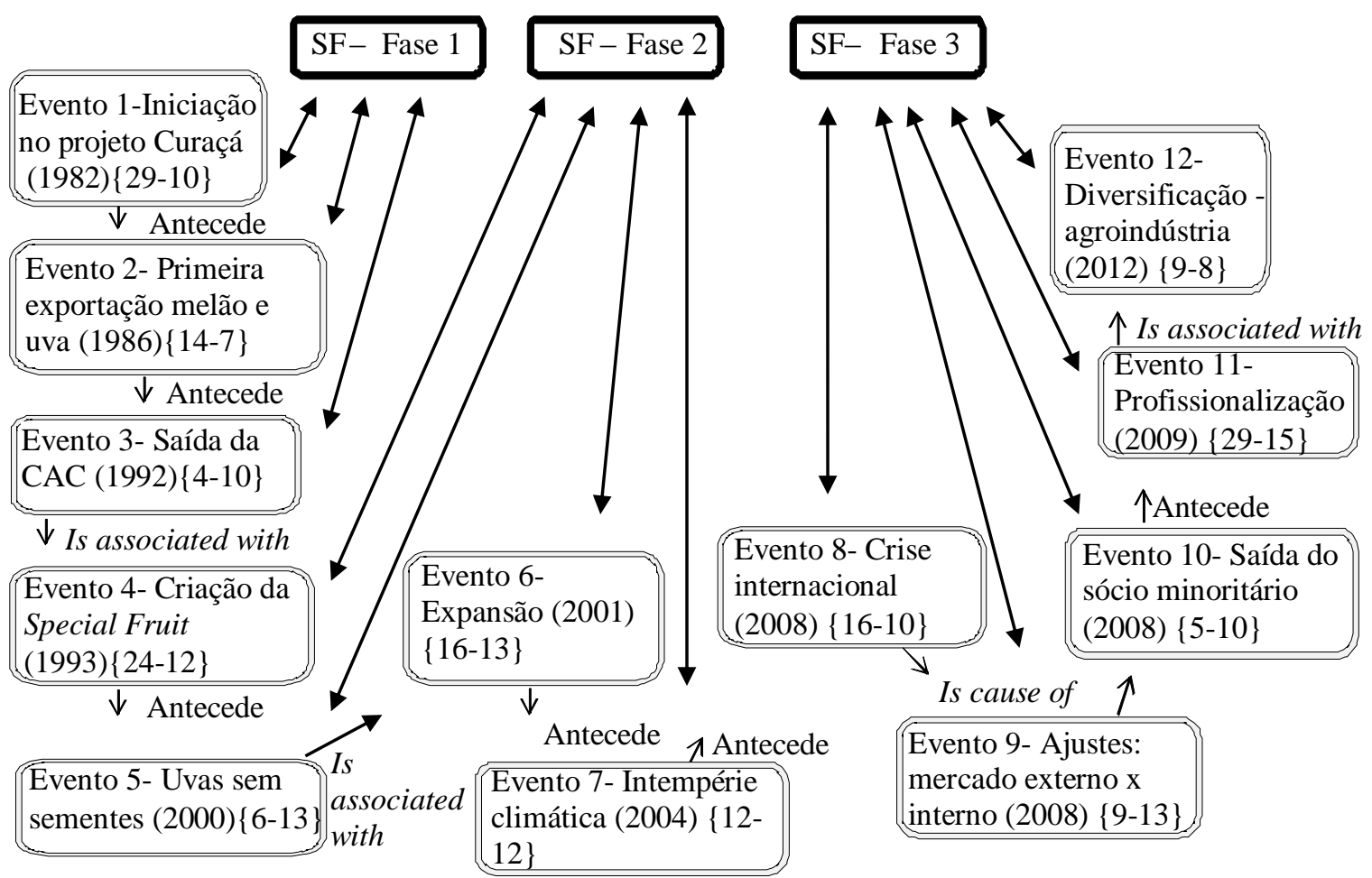

Figura 5. Processo de Internacionalização da Special Fruit (1982-2012).

Nota. Fonte: Elaborado pelos autores.

A Tabela 5 contempla o processo de internacionalização da empresa no período entre 1982 e 2012. Com isso, promove a observação da existência e da ausência das facetas do risco.

Tabela 5

Expressão das Facetas e as Características do Risco no Processo de Internacionalização da Special Fruit

\begin{tabular}{|c|c|c|c|c|c|c|c|c|c|c|c|c|}
\hline \multirow{3}{*}{ Facetas e suas características } & \multicolumn{4}{|c|}{ Fase 1} & \multicolumn{4}{|c|}{ Fase 2} & \multicolumn{4}{|c|}{ Fase 3} \\
\hline & \multicolumn{4}{|c|}{ 1982-1992 } & \multicolumn{4}{|c|}{ 1993-2007 } & \multicolumn{4}{|c|}{ 2008-2012 } \\
\hline & E1 & E2 & $\mathbf{E 3}$ & $\mathbf{E 4}$ & E5 & E6 & E7 & E8 & E9 & E10 & E11 & E12 \\
\hline \multicolumn{13}{|l|}{ Câmbio } \\
\hline \multicolumn{13}{|l|}{ Comercial e negociação } \\
\hline \multicolumn{13}{|l|}{ Condições climáticas } \\
\hline \multicolumn{13}{|l|}{ Empresa de grande porte } \\
\hline \multicolumn{13}{|l|}{ Produção agrícola } \\
\hline Variedades & & & & & & & & & & & & \\
\hline
\end{tabular}

Nota. Fonte: Elaborado pelos autores.

Na Figura 6, o risco se expressa no comercial e na negociação (câmbio), por ser uma empresa de grande porte e na produção agrícola (condições climáticas e variedades). O imigrante japonês (Entrevistado-PEeBA_25), proprietário da empresa, assumiu riscos diversos para manter a empresa competitiva frente aos concorrentes nacionais e internacionais, achado que fortalece o pensamento de Dimitratos e Plakoyiannaki (2003) acerca do papel do risco como uma dimensão de EI. 


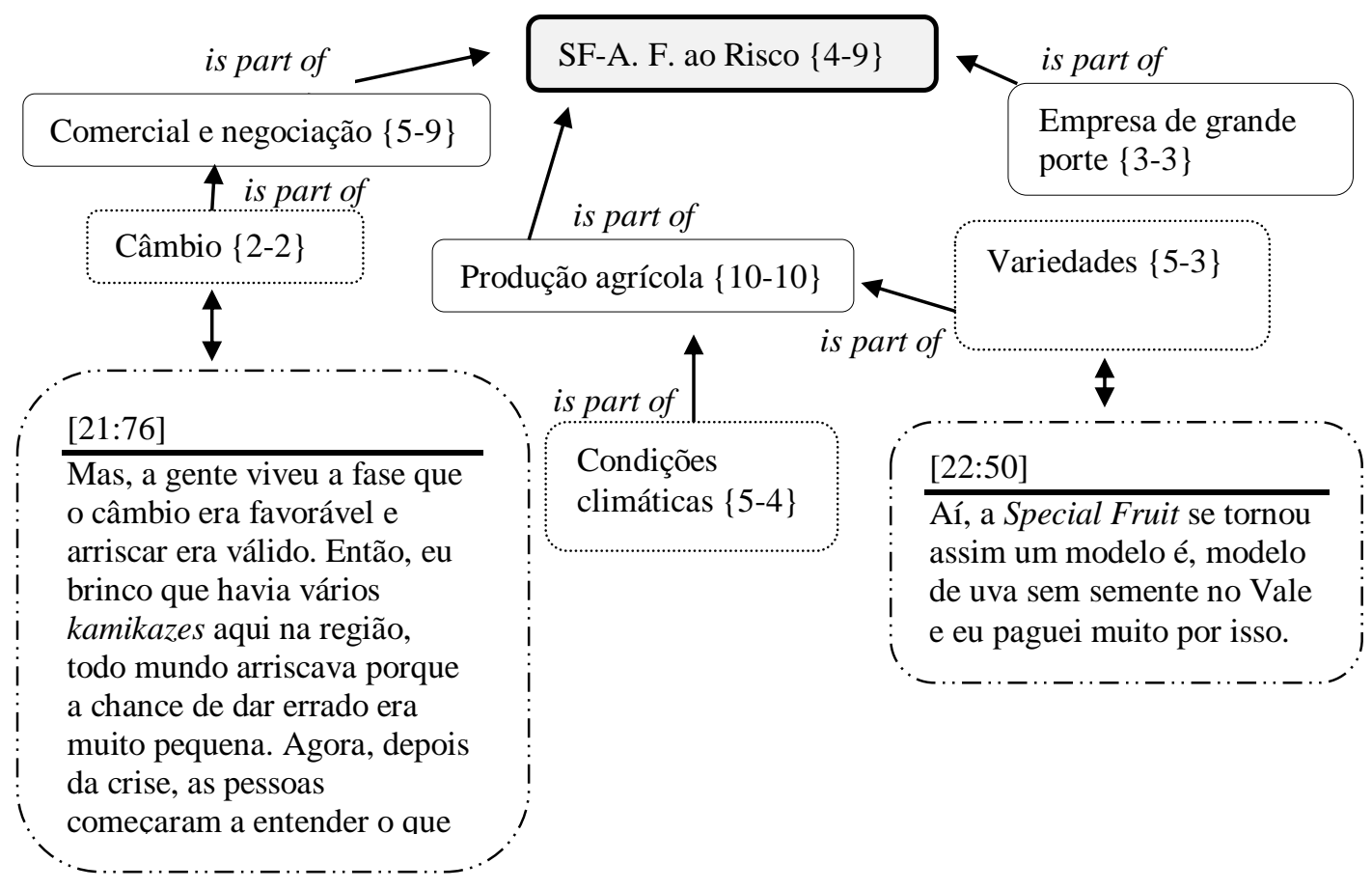

Figura 6. Facetas do Risco (Special Fruit).

Nota. Fonte: Elaborado pelos autores.

Destacando-se das empresas do polo RN/CE que garantem preço firme e adiantamento do comprador, na maior parte do tempo da internacionalização, o empreendedor do Vale do São Francisco se arriscava ao negociar as frutas em consignado, felizmente, tal conjuntura vem sendo modificada mais recentemente. Entretanto, no câmbio não se consegue ter tanto controle, o caráter volátil deixa o produtor refém para decidir se exporta ou não a fruta.

Na terceira e última fase da internacionalização, a Special Fruit alcança um patamar de grande empresa. Por consequência, o porte traz consigo mais riscos, como revelado por Dib (2008). A crise de 2008 foi preponderante para alertá-lo sobre esse aspecto, levando-o a incluir os filhos na operação da companhia e assim, também ajudá-lo no gerenciamento dos riscos.

\section{Ara Agrícola-PE}

Dentre as quatro empresas analisadas, a Ara Agrícola se distingue por ter menos tempo de existência e por ser uma unidade estratégica de negócio da corporação familiar Ara Empreendimentos (Barney, 2002). A fazenda onde está localizada a empresa foi adquirida, em 2004, com o objetivo de exportar uvas sem sementes (born global - Rennie, 1993), único produto cultivado desde a fundação e na safra, o empreendimento emprega aproximadamente mil funcionários para produzir em aproximadamente 180 hectares. O processo de internacionalização da empresa possui duas fases e sete eventos que podem ser visualizados na Figura 7. 


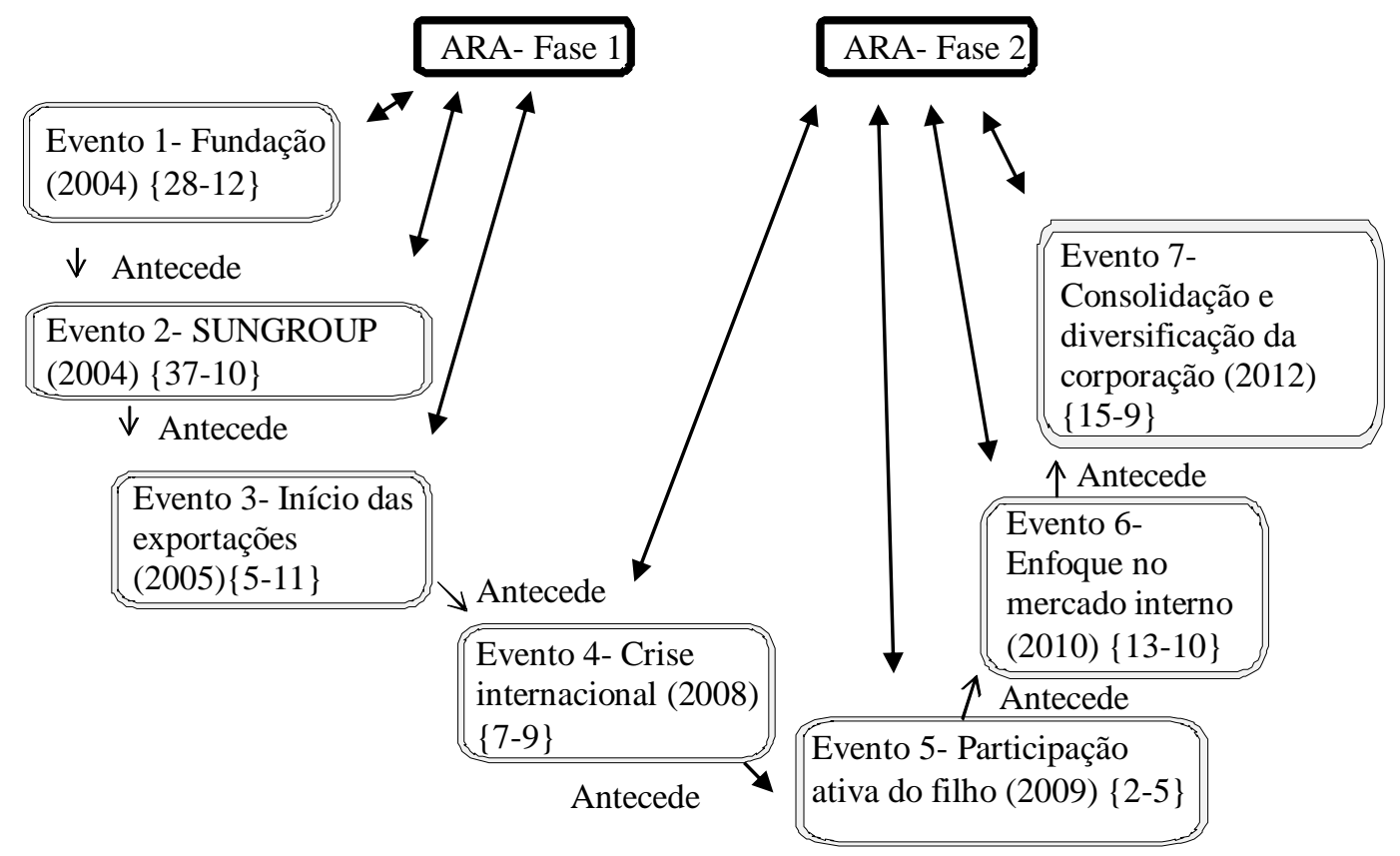

Figura 7. Processo de Internacionalização da Ara Agrícola (2004-2012).

Nota. Fonte: Elaborado pelos autores.

Apenas com oito anos de atividade, a Ara Agrícola tem a internacionalização desenvolvida em duas fases e sete eventos marcantes. Cabe esclarecer que a maior parte dos dados está relacionada ao empreendedor proprietário da empresa (Entrevistado-PEeBA_30), e na fase mais recente, algumas ações empreendedoras, especialmente em relação ao risco (ver Tabela 6), são implementadas em conjunto com o filho (Entrevistado-PEeBA_27).

Tabela 6

Expressão das Facetas e Características do Risco no Processo de Internacionalização da Ara Agrícola

\begin{tabular}{|c|c|c|c|c|c|c|c|}
\hline & \multicolumn{3}{|c|}{ Fase 1} & \multicolumn{4}{|c|}{ Fase 2} \\
\hline Facetas e suas & \multicolumn{3}{|c|}{ 2004-2007 } & \multicolumn{4}{|c|}{ 2008-2012 } \\
\hline & E1 & E2 & E3 & E4 & E5 & E6 & E7 \\
\hline \multicolumn{8}{|l|}{ Câmbio } \\
\hline \multicolumn{8}{|l|}{ Comercial e negociação } \\
\hline \multicolumn{8}{|l|}{ Condições climáticas } \\
\hline Produção agrícola & & & & & & & \\
\hline
\end{tabular}

Nota. Fonte: Elaborado pelos autores.

Não obstante o conhecimento adquirido de anos como empresário, o comércio exterior e a fruticultura não faziam parte do escopo de sua competência. Enfrentar os riscos concernentes à atividade foi desafiador, quais sejam: comercial e negociação (câmbio); e, produção agrícola (condições climáticas) (ver Figura 8). Para os gestores, os obstáculos são claros, todavia, para continuar no comércio exterior, é necessário ultrapassá-los. 


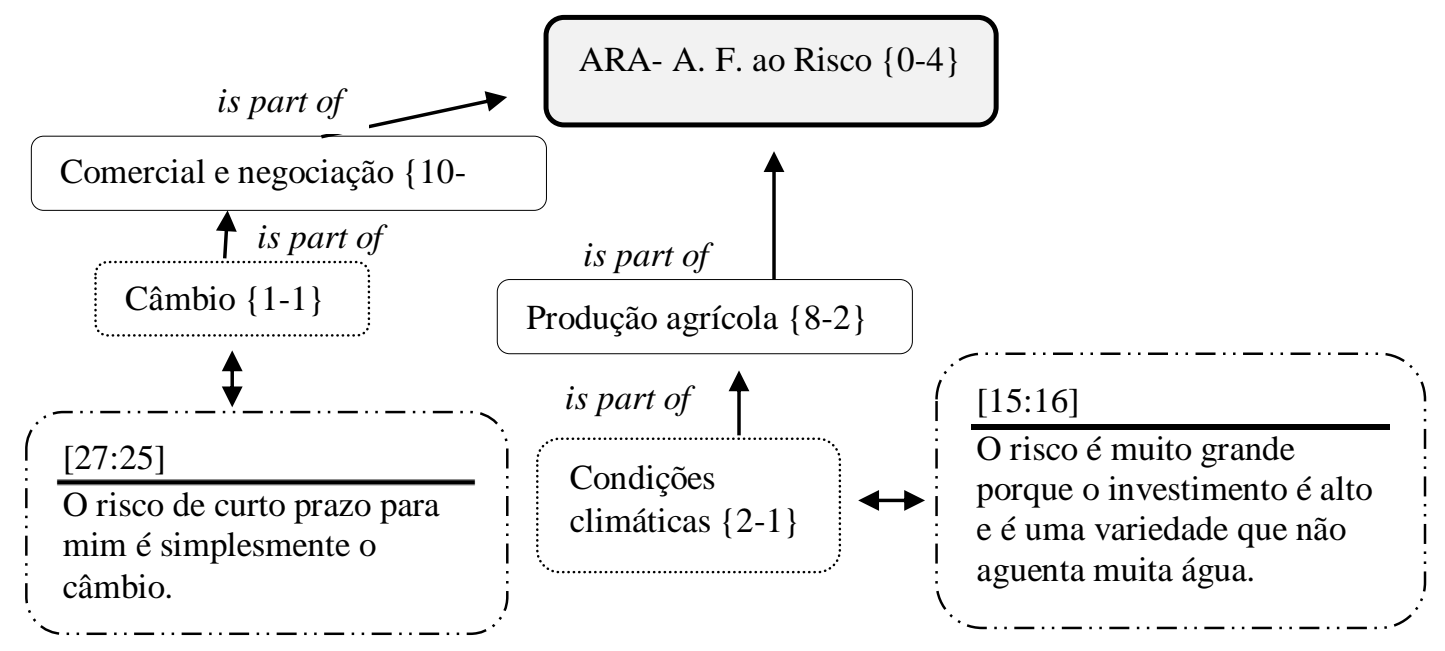

Figura 8. Facetas do Risco (Ara Agrícola).

Nota. Fonte: Elaborado pelos autores.

No entendimento de autores como Kiss, Danis e Cavusgil (2012), o risco é uma característica dos dirigentes de empresas internacionalizadas das nações emergentes. Para chegarem a essa conclusão, os autores revisaram diversas pesquisas realizadas nos países em desenvolvimento, percebendo que a instabilidade econômica é uma das principais causas que levam à maturação da habilidade de assumir riscos.

\section{Análise cruzada dos casos}

A Tabela 7 faz duas revelações: a confirmação da presença do risco e a identificação das facetas e suas características. Na primeira coluna, são apresentadas as facetas; na segunda, as características dessas facetas. A inexistência de características está representada nos quadros desta seção pelo símbolo -----------. A análise cruzada entre empresas permite afirmar que a comercialização e a negociação, assim como a produção agrícola, são os dois fatores que desafiam o empreendedor, levando-o ao enfrentamento de riscos. Indica-se que, na análise dos dados, foram consideradas as facetas e as características que estão presentes em três ou quatro empresas, sendo elas destacadas nas células acinzentadas. As facetas e características presentes em uma ou duas empresas (células brancas) são descartadas para fins desta análise.

Tabela 7

\section{Definição das Facetas do Risco}

\begin{tabular}{|c|c|c|c|c|c|}
\hline Facetas & Características das facetas & $\begin{array}{c}\text { Agrícola } \\
\text { Famosa }\end{array}$ & $\begin{array}{l}\text { Agro } \\
\text { Melão }\end{array}$ & $\begin{array}{c}\text { Special } \\
\text { Fruit }\end{array}$ & $\begin{array}{c}\text { Ara } \\
\text { Agrícola }\end{array}$ \\
\hline \multirow{2}{*}{$\begin{array}{l}\text { Comercial e } \\
\text { negociação }\end{array}$} & Câmbio & $\mathrm{X}$ & $\mathrm{X}$ & $\mathrm{X}$ & $\mathrm{X}$ \\
\hline & Novos mercados & $\mathrm{X}$ & & & \\
\hline \multirow[t]{3}{*}{ Produção agrícola } & Condições climáticas & $\mathrm{X}$ & $\mathrm{X}$ & $\mathrm{X}$ & $\mathrm{X}$ \\
\hline & Produção e parcerias no exterior & $\mathrm{X}$ & & & \\
\hline & Variedades & $\mathrm{X}$ & & $\mathrm{X}$ & \\
\hline Distribuição & 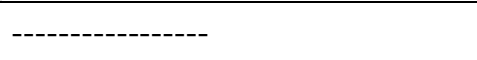 & $\mathrm{X}$ & $\mathrm{X}$ & & \\
\hline Empresa de grande porte & ----------------- & $\mathrm{X}$ & & $\mathrm{X}$ & \\
\hline
\end{tabular}

Nota. Fonte: Elaborado pelos autores. 
A comercialização e a negociação internacionais de frutas frescas, em sua essência, é arriscada, visto que se trata de produto altamente perecível. Mas, como se não fosse suficiente, mundialmente os compradores forçam transações em consignado benéficas para apenas um dos lados. Ademais, a ausência de contratos ou do cumprimento deles requer do empreendedor atitude de aceitação frente aos riscos, como propagado por Williamson (1995).

Existem, ainda, as questões em torno do câmbio, que estimulam ou desmotivam as exportações. A magnitude do Brasil, com o vasto mercado e aumento do poder de compra, permite que os produtores agrícolas se direcionem ao exterior quando o câmbio está favorável, ou diminuam esses lotes para o mercado internacional passando para o doméstico quando a moeda estrangeira está em baixa. Vale salientar que esse sistema está sendo melhor explorado nos últimos três anos devido à estabilidade econômica nacional e à melhoria de vida do brasileiro, possibilitando a absorção do produto. Todavia, mesmo com o cenário cambial favorável, os respondentes apontam como sendo este um elemento que requer empenho para enfrentá-lo. Tal compreensão está alinhada à proposta de Carvalho e Miranda (2009), que tratam o câmbio como um aspecto da economia que deve ser gerenciado pelas empresas do agronegócio.

Os investimentos, trabalho diário, condições do solo, disponibilidade de água são alguns dos fatores primordiais da produção agrícola. A condição climática faz parte dessa faceta e emerge dos dados como uma das categorias mais relevantes que colabora no cultivo de determinadas espécies. Sendo assim, as frutas tropicais específicas de locais de estiagem, como os que são encontrados no semiárido brasileiro, não suportam a presença de chuvas que causam manifestação de pragas e não permitem a obtenção de frutas de qualidade (Carvalho \& Miranda, 2009). Sobretudo, nesse âmbito, a "produção agrícola", aqui relacionada ao risco, desponta como particular da agricultura, o que não deve ser interpretado de forma restrita ao agronegócio, pois a produção ou operação nas empresas de outro segmento econômico podem ser relevantes para o EI.

Portanto, na análise de dados, identificam-se diversas ações empreendedoras traçadas para enfrentar as situações arriscadas no intento de internacionalizar (McCarthy \& Leavy, 1999). Desse modo, os achados fortalecem a proposta teórica de Dimitratos e Plakoyiannaki (2003), que apresentam o risco como uma categoria do EI.

\section{Considerações Finais}

Dentre os pontos comuns entre as empresas analisadas, identifica-se que todas são born globals e iniciaram a internacionalização nos primeiros anos de atividade. Este estudo fortalece a perspectiva que reconhece a associação do empreendedorismo internacional com as born globals. A Agrícola Famosa, a Agro Melão e a Ara Agrícola foram fundadas com esse propósito, diferentemente da Special Fruit, que se comprometeu a produzir uva itália para o mercado doméstico, no início de sua operação como agricultor familiar. Não obstante, tenha tido plano inicial distinto das demais, a concentração em adotar tecnologia de ponta na produção mostra-se comum às firmas analisadas, aspecto que colaborou na inserção internacional.

O macroambiente exerce influência na comercialização dos empreendimentos. O empreendedor efetua as transações globais enfrentando especialmente as variações cambiais que afetam o processo de internacionalização, assim como os riscos relacionados à produção, especialmente os derivados do clima. As chuvas, quando acontecem em períodos atípicos, comprometem a lavoura e a qualidade das frutas; além disso, a estiagem que se prolonga por mais de um ano afeta a irrigação e a produtividade. Essas evidências indicam que, no empreendedorismo internacional, a propensão ao enfrentamento de riscos é fundamental para iniciar e manter-se no cenário internacional.

De uma perspectiva teórica, este estudo traz algumas contribuições para a literatura acadêmica. Em primeiro lugar, é um dos poucos que examina o empreendedorismo internacional em firmas do 
agronegócio observando o risco, englobando a análise das estratégias, o processo de internacionalização e o contexto. A segunda contribuição teórica é a identificação de facetas do risco, reveladas como uma dimensão do EI. Ademais, os resultados permitem identificar que, dentre as principais facetas do risco, a dimensão comercial e a negociação advém de duas origens, da forma que o produto é transacionado internacionalmente, assim como da dinâmica da agricultura. Por outro lado, a faceta intitulada por produção agrícola é decorrente dos riscos do agronegócio.

\section{Nota}

${ }^{1}$ Texto apresentado e premiado como melhor artigo do VI Encontro de Estudos em Estratégia - 3Es (organizado pela ANPAD), realizado em Bento Gonçalves-RS.

\section{Referências}

Acs, Z., Dana, L.-P., \& Jones, M. V. (2003). Toward new horizons: the internationalisation of entrepreneurship. Journal of International Entrepreneurship, 1(1), 5-12.

Agrícola Famosa. (2012). Learn more about what our quality is made of. Icapuí, CE: Autor.

Bardin, L. (2011). Análise de conteúdo. São Paulo: Edições 70.

Barney, J. B. (2002). Gaining and sustaining competitive advantage (3rd ed.). New Jersey: PrenticeHall.

Bogdan, R. C., \& Biklen, S. K. (1994). Investigação qualitativa em educação. Porto: Porto Editora.

Butler, J. E., Doktor, R., \& Lins, F. A. (2010). Linking international entrepreneurship to uncertainty, opportunity discovery, and cognition. Journal of International Entrepreneurship, 8(2), 121-134. doi: 10.1007/s10843-010-0054-x

Carvalho, J. M., \& Miranda, D. L. (2009). As exportações brasileiras de frutas: um panorama atual. Anais do Congresso Brasileiro de Economia e Sociologia Rural, Porto Alegre, RN, Brasil, 47.

Child, J., \& Rodrigues, S. B. (2007, setembro). The role of trust in international entrepreneurship. Anais do Encontro da Associação Nacional de Pós-Graduação e Pesquisa em Administração, Rio de Janeiro, RJ, Brasil, 31.

Coombs, J. E., Sadrieh, F., \& Annavarjula, M. (2009). Two decades of international entrepreneurship research: what have we learned - where do we go from here? International Journal of Entrepreneurship, 13(1), 23-64.

Coviello, N. E., \& Jones, M. V. (2004). Methodological issues in international entrepreneurship research. Journal of Business Venturing, 19(4), 485-508. doi: 10.1016/j.jbusvent.2003.06.001

Coviello, N. E., McDougall, P. P., \& Oviatt, B. M. (2011). The emergence, advance and future of international entrepreneurship research: an introduction to the special forum. Journal of Business Venturing, 26(1), 625-631. doi: 10.1016/j.jbusvent.2011.07.002

Dib, L. A. (2008). O processo de internacionalização de pequenas e médias empresas e o fenômeno born global: estudo do setor de software no Brasil (Tese de doutorado). Programa de PósGraduação em Administração, Universidade Federal do Rio de Janeiro, Rio de Janeiro, RJ, Brasil. 
Dimitratos, P., \& Plakoyiannaki, E. (2003). Theoretical foundations of an international entrepreneurial culture. Journal of International entrepreneurship, 1(2), 187-215. doi: 10.1023/A:1023804318244

Eisenhardt, K. M. (1989). Building theories from case studies research. Academy Management Review, 14(4), 532-550.

Filion, L. J. (1999). Empreendedorismo: empreendedores e proprietários-gerentes de pequenos negócios. Revista de Administração, 34(2), 5-28.

Freitag, A. R., Filho, \& Amal, M. (2008, setembro). Estratégias e determinantes da internacionalização de pequenas e médias empresas (PMEs): abordagem da teoria de redes de relacionamento e empreendedorismo. Anais do Encontro da Associação Nacional de Pós-Graduação e Pesquisa em Administração, Rio de Janeiro, RJ, Brasil, 32.

Friese, S. (2012). Qualitative data analysis with ATLAS.ti. London: SAGE.

Grichnik, D. (2008). Risk choices in new ventures decisions: experimental evidence from Germany and the United States. Journal of International Entrepreneurship, 6(1), 22-47. doi: 10.1007/s10843008-0019-5

Guba, E. G., \& Lincoln, Y. S. (2005). Paradigmatic controversies, contradictions, and emerging confluences. In N. K. Denzin \& Y. S. Lincoln (Eds.), Handbook of qualitative research: third edition (pp. 191-215). London: Sage.

Johanson, J., \& Vahlne, J.-E. (2009). The uppsala internationalization process model revisited: from liability of foreignness to liability of outsidership. Journal of International Business Studies, 40(9), 1411-1431. doi: 10.1057/jibs.2009.24

Jones, M. V., Coviello, N., \& Tang, Y. K. (2011). International entrepreneurship research (1989-2009): a domain ontology and thematic analysis. Journal of Business Venturing, 26(1), 632-659. doi: 10.1016/j.jbusvent.2011.04.001

Keupp, M. M., \& Gassmann, O. (2009). The past and the future of international entrepreneurship: a review and suggestions for developing the field. Journal of Management, 35(3), 600-633. doi: $10.1177 / 0149206308330558$

Kiss, A. N., Danis, W. M., \& Cavusgil, S. T. (2012). International entrepreneurship research in emerging economies: a critical review and research agenda. Journal of Business Venturing, 27(2), 266-290. doi: 10.1016/j.jbusvent.2011.09.004

Leite, Y. V. P., \& Moraes, W. F. A. de (2012, setembro). Empreendedorismo internacional: proposição de um framework. Anais do Encontro da Associação Nacional de Pós-Graduação e Pesquisa em Administração, Rio de Janeiro, RJ, Brasil, 36.

Lumpkin, G. T., \& Dess, G. G. (1996). Clarifying the entrepreneurial orientation construct and linking it to performance. Academy of Management, 21(1), 135-172. doi: 10.5465/AMR.1996.9602161568

McCarthy, B., \& Leavy, B. (1999). The entrepreneur, risk-perception and change over time: a typology approach. IBAR, 20(1), 126-140.

McDougall, P. P. (1989). International versus domestic entrepreneurship: new venture strategic behavior and industry structure. Journal of Business Venturing, 4(6), 387-400.

Melin, L. (1992). Internationalization as a strategy process. Strategic Management Journal, 13(S2), 99118. doi: $10.1002 / \mathrm{smj} .4250130908$ 
Mello, R. C. de, Rocha, A. da, \& Maculan, A.-M. (2009, junho). A trajetória internacional das pequenas empresas: é possível conciliar as teorias comportamentais? Anais do Encontro de Estudos em Estratégia, Recife, PE, Brasil, 4.

Merriam, S. B. (1998). Qualitative research and case study applications in education. San Francisco: Jossey-Bass.

Ministério da Agricultura, Pecuária e Abastecimento. (2011a). Intercâmbio comercial do agronegócio: principais mercados de destino. Recuperado de http://www.agricultura.gov.br/arq_editor/file/MAIS\%20DESTAQUES/Agronegocio_2011.pdf

Ministério da Agricultura, Pecuária e Abastecimento. (2011b). Informes de produtos. Recuperado de http://www.agricultura.gov.br/internacional/indicadores-e-estatisticas/informes-de-produtos

Morrow, J. F. (1988). International entrepreneurship: a new growth opportunity. New Management, $5(3), 59-60$.

Mtigwe, B. (2006). Theoretical milestones in international business: the journey to international entrepreneurship theory. Journal of International Entrepreneurship, 4(1), 5-25. doi: $10.1007 / \mathrm{s} 10843-006-5872-5$

Nassif, V. M. J., Ghobril, A. N., \& Silva, N. S. da (2010). Understanding the entrepreneurial process: a dynamic approach. Brazilian Administration Review, 7(2), 213-226. Recuperado de http://www.scielo.br/pdf/bar/v7n2/v7n2a07.pdf. doi: 10.1590/S1807-76922010000200007

Oliveira, M. F. S. de (2011, setembro). El concepto del emprendedorismo: ¿todavía un problema? Anais do Encontro da Associação Nacional de Pós-Graduação e Pesquisa em Administração, Rio de Janeiro, RJ, Brasil, 35.

Oviatt, B. M., \& McDougall, P. P. (1994). Toward a theory of international new ventures. Journal of International Business Studies, 25(1), 45-64.

Paiva, F. G. de, Jr., Leão, A. L. M. S. de, \& Mello, S. C. B. de (2011). Validade e confiabilidade na pesquisa qualitativa em administração. Revista de Ciências da Administração, 13(31), 190-209. doi: 10.5007/2175-8077.2011v13n31p190

Patton, M. Q. (2001). Qualitative research and evaluation methods. California: Sage Publication.

Ramos, P. (Org.). (2007). Dimensões do agronegócio brasileiro: políticas, instituições e perspectivas. Brasília: MDA. Recuperado de http://www.estig.ipbeja.pt/ ac_direito/arquivo_345.pdf

Rennie, M. W. (1993). Born global. The McKinsey Quarterly, 1(4), 45-52.

Root, F. R. (1994). Design entry strategy for international markets. In F. R. Root, Entry strategies for international markets (Chap. 1, pp. 1-24). New York: Lexington Books.

Rossi, D. L. (2008). Dimensões do empreendedorismo internacional na internacionalização de uma empresa mineira do setor alimentício (Dissertação de mestrado). Programa de Pós-Graduação em Administração, Faculdade Novos Horizontes, Belo Horizonte, MG, Brasil.

Schweizer, R., Vahlne, J.-E., \& Johanson, J. (2010). Internationalization as an entrepreneurial process. Journal of International Entrepreneurship, 8(4), 343-370. doi: 10.1007/s10843-010-0064-8

Sharma, V. M., \& Erramilli, M. K. (2004). Resource-based explanation of entry mode choice. Journal of Marketing Theory and Practice, 12(1), 1-18.

Stake, R. E. (1995). The case of case study research. Thousand Oaks: Sage Publications. 
Strauss, A., \& Corbin, J. (2008). Basics of qualitative research: techniques and procedures for developing Grounded Theory (2nd ed.) Thounsand Oaks: Sage Publications.

Van de Ven, A. H. (1992). Suggestions for studing stratey process: a research note. Strategic Management Journal, 13(S1), 169-188. doi: 10.1002/smj.4250131013

Welch, C. L., \& Welch, L. S. (2004). Broadening the concept of international entrepreneurship: internationalization, networks and politics. Journal of International Entrepreneurship, 2(3), $217-$ 237. doi: 10.1023/B:JIEN.0000032774.01082.41

Williamson, O. E. (1995). Transaction cost economics and organization theory. In O. E. Williamson (Ed.), Organization theory from Chester Barnard to the present and beyond (Exp. ed., pp. 207256). New York: Oxford University Press.

Zahra, S. A., \& George, G. (2002). International entrepreneurship: the current status of field and future research agenda. In M. A. Hitt, R. D. Ireland, D. L. Sexton, \& S. M. Amp (Eds.), Strategic entrepreneurship, creating a new mindset (pp. 255-288). Oxford, UK: Blackwell. 